\title{
Study of Membrane Transport for Hemodiafilter and Reverse Osmosis Module
}

\author{
Masaaki Sekino*
}

Toyobo Co., Ltd., 2-2-8 Dojima Hama, Kita-ku, Osaka 530-8230, Japan

\begin{abstract}
As a typical membrane technology by which the solute substances are separated from a solution, hemodiafilter and reverse osmosis module are studied, in particular regarding the solute transport through the membrane. The solute transport equation, as a key point of this paper, could be derived from the modified KedemKatchalsky equation combined with Film theory model. As the next key point for the numerical analysis, the solute transport equation was inserted into the previous module model, and the differential equations composing this module model were converted to the difference equations calculated with a nonlinear secant method. Then the solute concentration profiles of the membrane and the boundary layers in the hemodiafilter and the reverse osmosis module were obtained to visually illustrate in Figures $\mathbf{3}$ to $\mathbf{6}$. Finally, it was clear that the occurrence of concentration polarization in the boundary layer is dependent on values of the membrane parameters, including solute permeability $\left(P_{\mathrm{m}}\right)$ and reflection coefficient $(\sigma)$, the ultrafiltration flux $\left(J_{\mathrm{v}}\right)$ and the mass transfer coefficient $(k)$.
\end{abstract}

Keywords: Mass transfer, concentration polarization, membrane transport, reverse osmosis, hemodiafiltration.

\section{INTRODUCTION}

At present, the hemodiafilter for medical use and the reverse osmosis module for the desalination market are widely used throughout the world, having similar functions in solute transport mechanisms removing solutes from a solution. In this paper the separation systems for these two modules are comparatively and consistently discussed in view of the transport models and the profiles of solute concentration at boundary layers. A numerical analysis is carried out with the solute transport equation to be newly derived through the modified Kedm-Katchalsky equation taken the concentration polarization into account.

The behavior of these concentration polarization phenomena are calculated by computer modeling and illustrated later. The hemodiafilter and the reverse osmosis module, which are the objects of this study, are made of hollow fiber membranes.

\section{MEMBRANE TRANSPORT MODEL}

Kedem and Katchalsky [1] derived the phenomenological transport equation based on the theory of irreversible thermodynamics as follows:

$$
\begin{aligned}
& J_{\mathrm{V}}=L_{\mathrm{P}}(\Delta P-\sigma \Delta \Pi) \\
& J_{\mathrm{S}}=\omega \Delta \Pi+(1-\sigma) C_{\mathrm{lm}} J_{\mathrm{V}}
\end{aligned}
$$

\footnotetext{
*Address correspondence to this author at the Toyobo Co., Ltd., 2-2-8 Dojima Hama, Kita-ku, Osaka 530-8230, Japan; Tel: +81-6-6348-3248;

Fax: +81-6-6348-3237; E-mail: masaaki_sekino@toyobo.jp
}

where the first and second terms on the right side of equation (2) are called the diffusive and convecitive flux terms respectively, and $C_{\mathrm{lm}}$ is the logarithmic mean solute concentration in the membrane. However, it has some issues with the dependence on solute fluxes, so Spiegler and Kedem [2] rewrote equation (2) in differencial form across the thickness of the membrane:

$J_{\mathrm{S}}=-D_{\mathrm{M}} \frac{\mathrm{d} C}{\mathrm{~d} x}+J_{\mathrm{v}} \gamma C$

$y$ is the solute convective coefficient and $\gamma=1-\sigma$ here.

Equation (3) can be integrated [3] to give equation (4):

$J_{\mathrm{S}}=J_{\mathrm{v}} \gamma \frac{C_{\mathrm{BW}}+C_{\mathrm{DW}}}{2}+J_{\mathrm{v}} \gamma \frac{C_{\mathrm{BW}}-C_{\mathrm{DW}}}{2} \frac{\exp (P e)+1}{\exp (P e)-1}$

where $P e$ is the Peclet number calculated by $P e=J_{V} Y / P_{\mathrm{m}}$.

Equation (4) can be rearranged to a form similar to equation (2) as follows:

$J_{\mathrm{S}}=P_{\mathrm{m}}\left(C_{\mathrm{BW}}-C_{\mathrm{DW}}\right)+J_{\mathrm{v}} \gamma \bar{C}$

$\bar{C}=C_{\mathrm{BW}}-f\left(C_{\mathrm{BW}}-C_{\mathrm{DW}}\right)$

$f=\frac{1}{P e}-\frac{1}{\exp (P e)-1}$

When applying equation (5) to a practical membrane system, it should be considered how the solute flux transfers through the boundary layer, adding membrane transport equation (5). Equation (8) has 
been shown in this boundary layer according to Film theory [4].

$$
J_{\mathrm{S}}=-D_{\mathrm{L}} \frac{\mathrm{d} C}{\mathrm{~d} x}+J_{\mathrm{v}} C
$$

Equation (8) is then integrated over the boundary layer, applying the boundary conditions $C=C_{\mathrm{B}}$ at $x=-\delta_{\mathrm{B}}$ and $C=C_{\mathrm{BW}}$ at $x=0$ for the blood-side in the hemodiafiltration membrane.

$$
C_{\mathrm{BW}}=\left(C_{\mathrm{B}}-\frac{J_{\mathrm{S}}}{J_{\mathrm{V}}}\right) \exp \left(\frac{J_{\mathrm{V}}}{k_{\mathrm{B}}}\right)+\frac{J_{\mathrm{S}}}{J_{\mathrm{V}}}
$$

An analogous procedure can be used on the dialysate-side in the hemodiafiltration membrane, applying the boundary conditions $C=C_{\mathrm{DW}}$ at $x=t$ and $C=C_{\mathrm{D}}$ at $x=t+\delta_{\mathrm{D}}[5]$.

$C_{\mathrm{DW}}=\left(C_{\mathrm{D}}-\frac{J_{\mathrm{S}}}{J_{\mathrm{V}}}\right) \exp \left[-\frac{J_{\mathrm{V}}}{k_{\mathrm{D}}\left(d_{\mathrm{O}} / d_{\mathrm{I}}\right)}\right]+\frac{J_{\mathrm{S}}}{J_{\mathrm{V}}}$

Equations (9) and (10) are substituted into equation (5) and then arranged in the same form as equation (5) [6]:

$$
J_{\mathrm{S}}=K_{\mathrm{O}}\left(C_{\mathrm{B}}-C_{\mathrm{D}}\right)+J_{\mathrm{v}} \gamma\left(f_{\mathrm{B}} C_{\mathrm{B}}+f_{\mathrm{D}} C_{\mathrm{D}}\right)
$$

where $K_{\mathrm{O}}$ is the overall mass transfer coefficient, and $f_{\mathrm{B}}$ and $f_{\mathrm{D}}$ are the blood-side and dialysate-side concentration factors.

$$
\frac{1}{K_{\mathrm{O}}}=\frac{1}{k_{\mathrm{B}}}+\frac{1}{P_{\mathrm{m}}\left(d_{\mathrm{lm}} / d_{\mathrm{I}}\right)}+\frac{1}{k_{\mathrm{D}}\left(d_{\mathrm{O}} / d_{\mathrm{I}}\right)}
$$

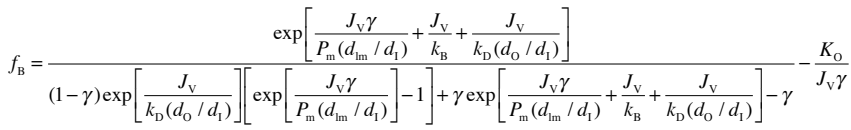

$$
f_{\mathrm{D}}=\frac{-1}{(1-\gamma) \exp \left[\frac{J_{\mathrm{v}}}{k_{\mathrm{D}}\left(d_{\mathrm{O}} / d_{\mathrm{1}}\right)}\right]\left[\exp \left[\frac{J_{\mathrm{v}} \gamma}{P_{\mathrm{m}}\left(d_{\mathrm{lm}} / d_{\mathrm{1}}\right)}\right]-1\right]+\gamma \exp \left[\frac{J_{\mathrm{v}} \gamma}{P_{\mathrm{m}}\left(d_{\mathrm{lm}} / d_{\mathrm{I}}\right)}+\frac{J_{\mathrm{v}}}{k_{\mathrm{B}}}+\frac{J_{\mathrm{v}}}{k_{\mathrm{D}}\left(d_{\mathrm{o}} / d_{\mathrm{I}}\right)}\right]-\gamma}+\frac{K_{\mathrm{o}}}{J_{\mathrm{v}} \gamma}
$$

In above equations (10), (12) - (14), $J_{V}$ and $J_{S}$ should be modified at a point of radial coordinate because the hollow fiber membrane forms a cylindrical surface. If the blood-side membrane surface is selected as the basis, $J_{V}$ and $J_{S}$ in the membrane and in the dialysate-side boundary layer are revised by multiplying by $d_{l} / d_{\mathrm{im}}$ and $d_{l} / d_{0}$ respectively.
The concentration boundary layer does not exist on the permeate side of the membrane in the revere osmosis module corresponding to the dialysate-side boundary layer in the hemodiafilter, so equation (10) may be ignored in reverse osmosis. Moreover, $J_{S}$ in equation (5) is composed of only the diffusive flux term, since $\sigma$ is usually very close to one (that is $\gamma=0$ ) if the solute substance is inorganic ions in the reverse osmosis process $[7,8]$.

Therefore, it could be expressed that the KedemKatchalsky equation is the same as the following Solution-Diffusion equation if $\sigma=1$ or $\gamma=0$ in equations (1) and (5):

$$
\begin{aligned}
& J_{\mathrm{v}}=A(\Delta P-\Delta \Pi) \\
& J_{\mathrm{S}}=B\left(C_{\mathrm{BW}}-C_{\mathrm{D}}\right)
\end{aligned}
$$

when recognized that $L_{\mathrm{p}}=A$ and $P_{\mathrm{m}}=B$.

The solute concentration on the permeate-side membrane is given as the following, assuming $J_{S} / J_{V}=C_{D}$ in equation (9):

$C_{\mathrm{BW}}-C_{\mathrm{D}}=\left(C_{\mathrm{B}}-C_{\mathrm{D}}\right) \exp \left(\frac{J_{\mathrm{V}}}{k_{\mathrm{B}}}\right)$

By substituting equation (17) into equation (16), solute flux $J_{S}$ is rewritten as:

$J_{\mathrm{S}}=B \exp \left(\frac{J_{\mathrm{V}}}{k_{\mathrm{B}}}\right)\left(C_{\mathrm{B}}-C_{\mathrm{D}}\right)$

Finally, it was demonstrated that the membrane transport model for both hemodiafiltration and reverse osmosis could be derived from the modified kedemKatchalsky equation with consideration of the concentration polarization.

Three predicted patterns of solute concentration in the membrane and the boundary layers are illustrated in Figure 1, which include (a) hemodialysis and hemodiafiltration, (b) hemodiafiltration and (c) reverse osmosis. It may be considered that the concentration polarization phenomenon occurs in pattern (b) and (c) as the ultrafiltration flux $J_{V}$ is larger. In this schematic diagram, the shaded region surrounded with solid lines, and the regions between the solid and dotted lines show the membrane itself, and the boundary layers, respectively. 


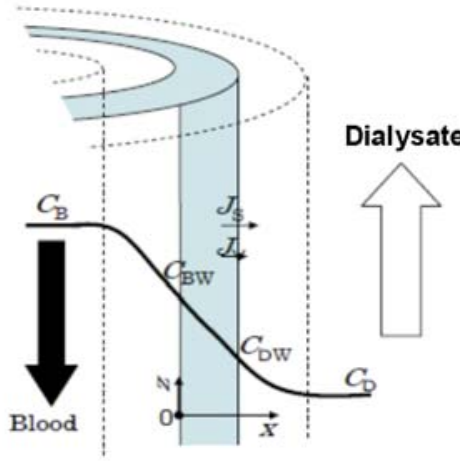

(a) Hemodialysis and Hemodiafiltration

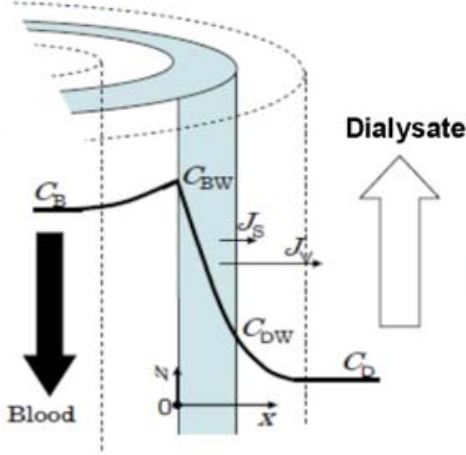

(b) Hemodiafiltration

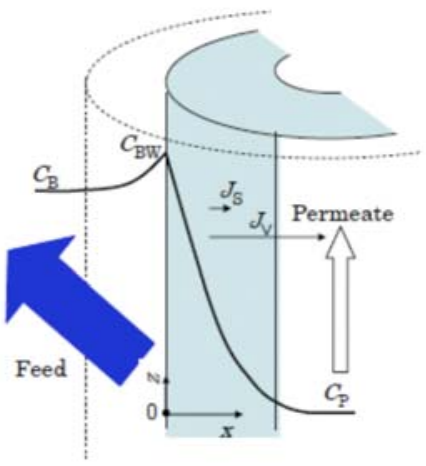

(c) Reverse Osmosis

Figure 1: Schematic for solute concentration profiles of hemodiafilter and reverse osmosis module.

\section{ANALYSIS}

To verify whether each membrane transport model meets actual membrane performance data in the hemodiafiler and the reverse osmosis module, it is essential to put them into the module model including pressure drop equations, mass balance equations and so on. The component equations for the reverse osmosis module model, introduced from the Toyobo $\mathrm{RO}$ module [9] and the hemodiafilter analysis model, presented by authors [10], are shown in Table 1.
Here, the mass transfer coefficients of the boundary layers are described. Shell-side mass transfer coefficient $k_{\mathrm{B}}$ in reverse osmosis was given from the experimental data of the Toyobo RO module [9].

$k_{\mathrm{B}}=0.048 R e^{0.6} S c^{1 / 3}\left(D_{\mathrm{LE}} / d_{\mathrm{O}}\right)$

In hemodiafiltration, the shell-side mass transfer coefficient was obtained from several commercialized dialyzers [11].

Table 1: Mathematical Equations Applied to Hollow Fiber Modules

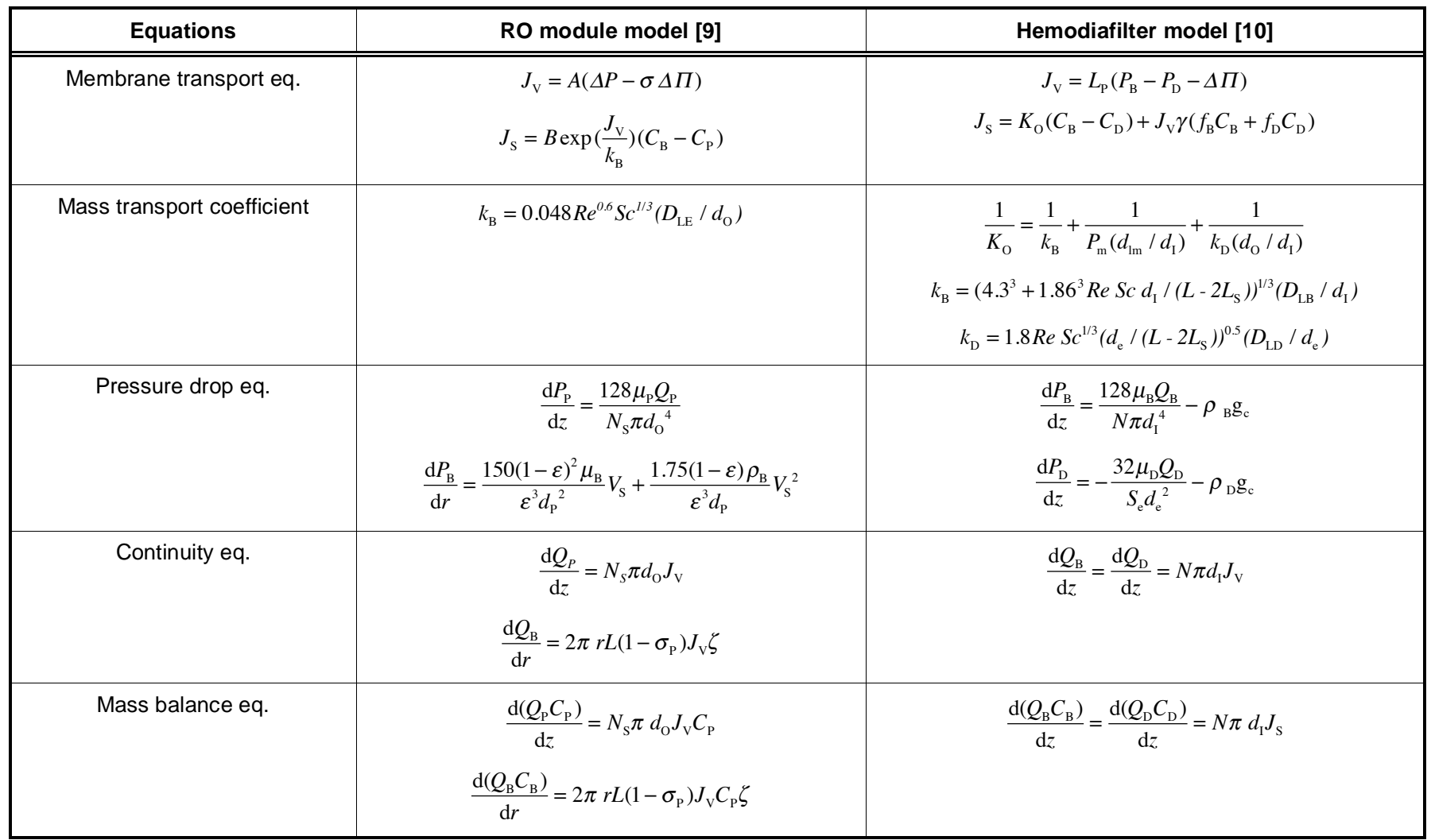




$$
k_{\mathrm{D}}=1.8 \operatorname{ReSc}^{1 / 3}\left(d_{\mathrm{e}} /\left(L-2 L_{\mathrm{S}}\right)\right)^{0.5}\left(D_{\mathrm{LD}} / d_{\mathrm{e}}\right)
$$

The bore-side mass transfer coefficient in the hemodiafilter was drawn [10] by combining two equations derived by Colton [12] and Keller [13].

$k_{\mathrm{B}}=\left(4.3^{3}+1.86^{3} \operatorname{ReSc} d_{\mathrm{I}} /\left(L-2 L_{\mathrm{S}}\right)\right)^{1 / 3}\left(D_{\mathrm{LB}} / d_{\mathrm{I}}\right)$

Bore-side flow of the hollow fiber can be explained by Poiseuille's law in both the reverse osmosis module and the hemodiafilter. Meanwhile, the Ergun equation was adopted in shell-side flow of Toyobo RO module whose fiber arrangement is considered to be approximate to that of a packed column. In the hemodiafiter analysis model, the gravity force term is given to the right-side of the pressure drop equation by considering that the hemodiafilter is usually installed vertically and so accepts the influence of the potential head for the entire length.

Generally the shell-side feed flow in the reverse osmosis module is a radial flow, and that in the hemodiafilter is parallel to the blood flow in hollow fiber. Accordingly, the continuity and mass balance equations of the hemodiafilter could be described under one-dimensional mode, while in the reverse osomosis module they needed two-dimensional mode.

The main objective of this paper is to estimate the solute concentration profiles in the membrane and the boundary layer and discuss them. The solute concentration in the membrane is given from equation (3) with boundary conditions that $C=C_{\mathrm{BW}}$ at $x=0$ and $C=C_{\text {DW }}$ at $x=t$, as follows:

$$
\begin{aligned}
& C=\frac{C_{\mathrm{BW}}+C_{\mathrm{DW}}}{2}-\frac{C_{\mathrm{BW}}-C_{\mathrm{DW}}}{2} \zeta ; 0 \leqq x \leqq t \\
& \zeta=\frac{2 \exp \left[\frac{J_{\mathrm{v}} \gamma X}{P_{\mathrm{m}} t\left(d_{\mathrm{lm}} / d_{\mathrm{I}}\right)}\right]-\exp \left[\frac{J_{\mathrm{v}} \gamma}{P_{\mathrm{m}}\left(d_{\mathrm{lm}} / d_{\mathrm{I}}\right)}\right]-1}{\exp \left[\frac{J_{\mathrm{v}} \gamma}{P_{\mathrm{m}}\left(d_{\mathrm{lm}} / d_{\mathrm{I}}\right)}\right]-1}
\end{aligned}
$$

In reverse osmosis $C$ can be calculated by equations (22) and (23) assuming that $C_{D W}$ and $V$ correspond to $C_{\mathrm{P}}$ and $C_{\mathrm{P}} / C_{\mathrm{BW}}$.

In the meantime, the solute concentration in the boundary layer is derived from equation (8). The feedside boundary condition in the reverse osmosis module and the blood-side one in the hemodiafilter are such that $C=C_{\mathrm{BW}}$ at $x=0$.

$$
C=\left(C_{\mathrm{BW}}-\frac{J_{\mathrm{S}}}{J_{\mathrm{V}}}\right) \exp \left[\frac{J_{\mathrm{V}}}{D_{\mathrm{LB}}} x\right]+\frac{J_{\mathrm{S}}}{J_{\mathrm{V}}} ; \quad \delta_{\mathrm{B}} \leqq x \leqq 0
$$

\begin{tabular}{|c|c|c|c|c|}
\hline Module & $\operatorname{HDF}\left(L_{P}=50\right)^{\star}$ & $\operatorname{HDF}\left(L_{P}=15\right)^{\star}$ & RO $(B W)^{*}$ & RO(SW)* \\
\hline \multirow[t]{2}{*}{ Membrane properties } & $\begin{array}{c}L_{\mathrm{P}}=50 \\
P_{\mathrm{m}}=3.9 \times 10^{-6} \\
\mathrm{\gamma}=0.8\end{array}$ & $\begin{array}{c}L_{\mathrm{p}}=15 \\
P_{\mathrm{m}}=0.34 \times 10^{-6} \\
\mathrm{Y}=0.3\end{array}$ & \multirow{2}{*}{$\begin{array}{c}A=9.80 \times 10^{-10} \\
B=2.48 \times 10^{-8} \\
(y \fallingdotseq 0) \\
d_{l}=77 \times 10^{-6} \\
d_{0}=160 \times 10^{-6}\end{array}$} & $\begin{array}{c}A=2.89 \times 10^{-10} \\
B=8.12 \times 10^{-10} \\
\quad(Y \fallingdotseq 0)\end{array}$ \\
\hline & \multicolumn{2}{|c|}{$\begin{array}{l}d_{l}=200 \times 10^{-6} \\
d_{0}=250 \times 10^{-6}\end{array}$} & & $\begin{array}{r}d_{1}=70 \times 10^{-6} \\
d_{0}=163 \times 10^{-6}\end{array}$ \\
\hline \multirow[t]{2}{*}{ Module specifications } & \multirow{2}{*}{\multicolumn{2}{|c|}{$\begin{array}{c}D_{\mathrm{O}}=0.035 \\
L=0.25 \\
\sigma_{\mathrm{P}}=0.52 \\
S=1.5\end{array}$}} & \multicolumn{2}{|c|}{$\begin{array}{c}D_{\mathrm{O}}=0.19 \\
L=1.06 \\
\sigma_{\mathrm{P}}=0.55\end{array}$} \\
\hline & & & $S=368$ & $S=361$ \\
\hline \multirow[t]{2}{*}{ Operating conditions } & \multirow{2}{*}{\multicolumn{2}{|c|}{$\begin{array}{c}C_{\mathrm{F}}=10 \mathrm{mg} / \mathrm{dl} \\
\text { myoglobin sol. } \\
P_{B}=200 \mathrm{mmHg} \\
Q_{F}=0,30,60 \mathrm{~cm}^{3} / \mathrm{min} \\
Q_{B}=200 \mathrm{~cm}^{3} / \mathrm{min} \\
Q_{D}=500 \mathrm{~cm}^{3} / \mathrm{min} \\
T_{F}=37 \mathrm{degC}\end{array}$}} & $\begin{array}{c}C_{\mathrm{F}}=1500 \mathrm{mg} / \mathrm{l} \\
\mathrm{NaCl} \text { sol. } \\
P_{\mathrm{F}}=1,2,3 \mathrm{MPa}\end{array}$ & $\begin{array}{c}C_{\mathrm{F}}=35000 \mathrm{mg} / \mathrm{l} \\
\mathrm{NaCl} \mathrm{sol} . \\
P_{\mathrm{F}}=5.5,6.5,7.5 \mathrm{MPa}\end{array}$ \\
\hline & & & & \\
\hline
\end{tabular}

The dialysate-side boundary condition in the hemodiafilter is such that $C=C_{\mathrm{DW}}$ at $x=t$.

Table 2: Premised Input Data for Calculation

${ }^{*} \operatorname{HDF}\left(L_{P}=50\right)$; High flux type hemodiafilter, $\operatorname{HDF}\left(L_{P}=15\right)$; Conventional type hemodiafilter, $R O(B W)$; Brackish water desalination type $R O, R O(S W)$; Seawater desalination type RO. 
$C=\left(C_{\mathrm{DW}}-\frac{J_{\mathrm{S}}}{J_{\mathrm{V}}}\right) \exp \left[\frac{J_{\mathrm{V}}}{D_{\mathrm{LD}}} \cdot \frac{x-t}{d_{\mathrm{O}} / d_{\mathrm{I}}}\right]+\frac{J_{\mathrm{S}}}{J_{\mathrm{V}}} ; \quad t \leqq x \leqq t+\delta_{\mathrm{D}}$

The solute concentration profiles are drawn by computing equations (22) to (25) on each membrane transport equation in the analysis model for the modules shown in Table 1. The premised data used for calculation of the module models is listed in Table 2. They are membrane properties, module geometries and operating conditions, which are quoted from literature [9,10]. Numerical calculations were put through by the computer algorithms which include the difference method for solving the differential equations shown in Table 1. Equations (22) to (25) were calculated simultaneously in the subroutine program for simulating the membrane transport equations. For instance, the computer calculation flow chart for the reverse osmosis module analysis model is indicated in Figure 2.

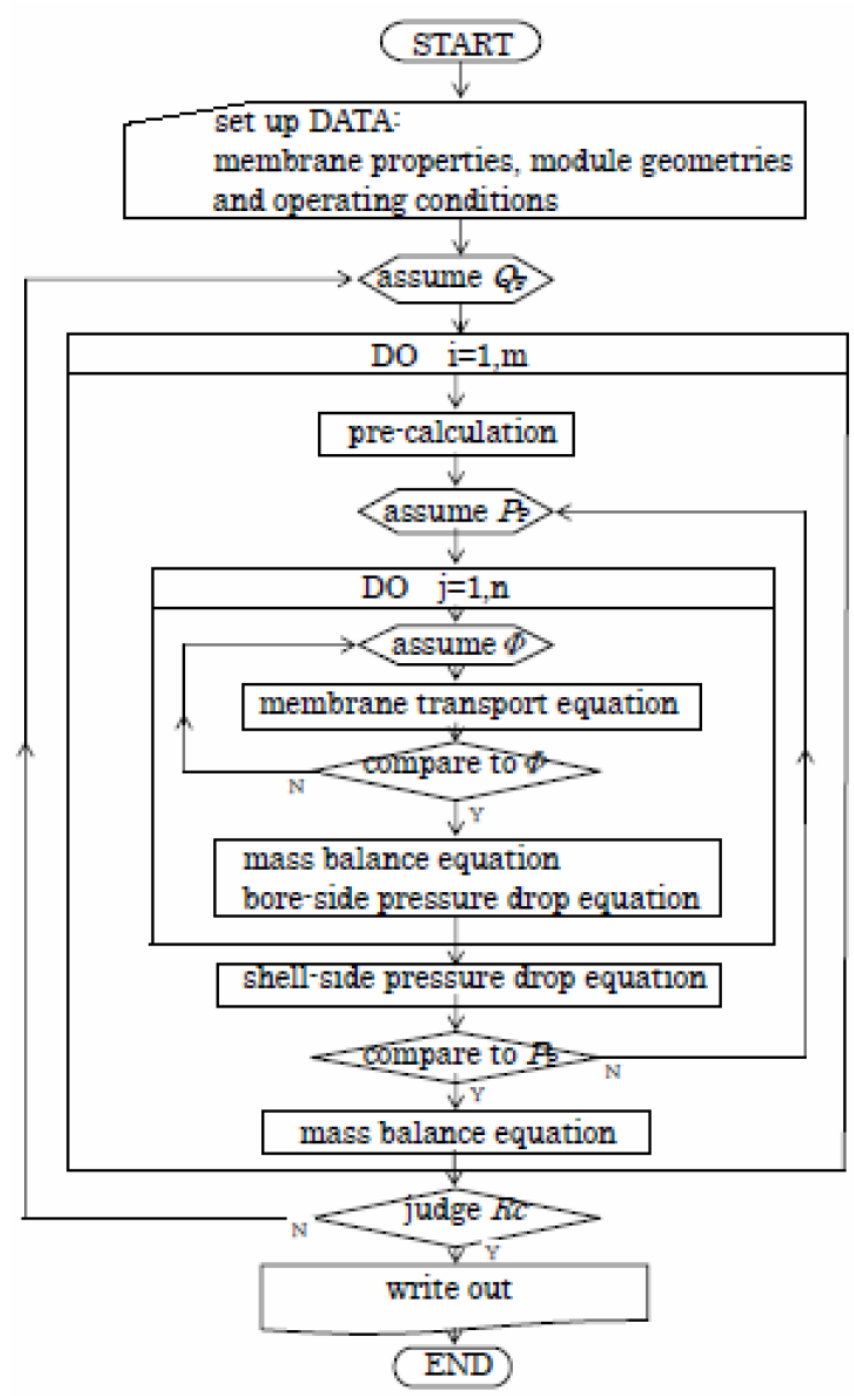

Figure 2: Computer flow diagram for $\mathrm{RO}$ module model.

\section{RESULTS AND DISCUSSION}

Figures 3 to 6 illustrate the calculation results of the solute concentration profiles. In these figures horizontal axis and vertical axis show the displacement perpendicular to the membrane and the solute concentration, respectively. The parameters in the figures indicate axial direction on the hemodiafilter and radial direction on the reverse osmosis module. The solute concentration profiles in hemodiafiltration where the ultrafiltration flow rate $Q_{p}$ of 0,30 and $60 \mathrm{~cm}^{3} / \mathrm{min}$ and the hydraulic permeability $L_{p}$ of 15 and 50 $\mathrm{mL} / \mathrm{m}^{2} \mathrm{hrmmHg}$ were set for the high molecular weight solute, myoglobin, are shown in Figures 3 and 4. TMP is the trans-membrane pressure, using a practical unit for easier understanding. Typical dialysis profiles of the solute concentration were obtained from a high flux type hemodiafilter $\left(L_{p}=50 \mathrm{~mL} / \mathrm{m}^{2} \mathrm{hrmmHg}\right)$, that is the solute concentrations gradually decrease along the blood-side boundary layer, the membrane, and the dialysate-side boundary layer as shown in Figure 3. A conventional type hemodiafilter $\left(L_{P}=15\right.$ $\mathrm{mL} / \mathrm{m}^{2} \mathrm{hrmmHg}$ ), which has lower solute permeability $P_{\mathrm{m}}$ than that of a high flux type causes stronger resistance of the membrane, so that the concentration polarization of the membrane occurs sharply as the ultrafiltration flow rate increases (see Figure 4). That is, as the Peclet number becomes larger, the concentration polarization level accelerates. In Figures 3 and $\mathbf{4}$, the blood-side boundary layer, the membrane itself and the dialysate-side boundary layer are in the left region between the dotted and solid lines, the middle region between the two solid lines, and the right region between the solid and dotted lines, respectively.

Figures 5 and 6 indicate the solute concentration profiles in the brackish water desalination type and the seawater desalination type reverse osmosis module, respectively. In these reverse osmosis modules, the phenomena of concentration polarization exists clearly due to the large membrane resistance. As the ultrafiltration flow rate (productivity) $Q_{P}$ increases by raising the applied pressure $P_{\mathrm{F}}$, the concentration polarization accelerates like in the $L_{p}=15$ hemodiafilter. Here, the thickness of the boundary layer, which is indicated by dotted line was estimated by a hollow fiber group model [14].

Finally, the numerical pointed output of the calculation results corresponding to Figures 3 to 6 are listed in Table 3. It is recognized that the concentration polarization occurs as the Peclet number is more than about 0.5 and naturally when the concentration 
$Q_{P}=0 \mathrm{~cm}^{3} / \mathrm{min}$

$T M P=22.0 \mathrm{mmHg}$

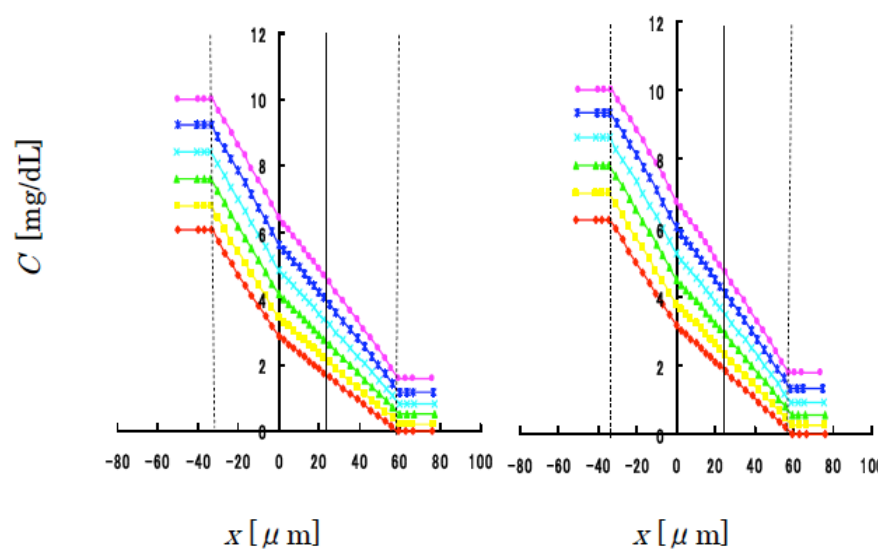

$Q_{P}=60 \mathrm{~cm}^{3} / \mathrm{min}$

$T M P=73.0 \mathrm{mmHg}$

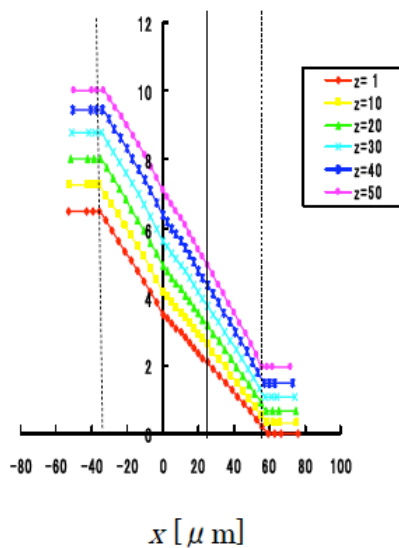

Figure 3: Solute concentration profiles of myoglobin for $L_{P}=50$ hemodiafilter.

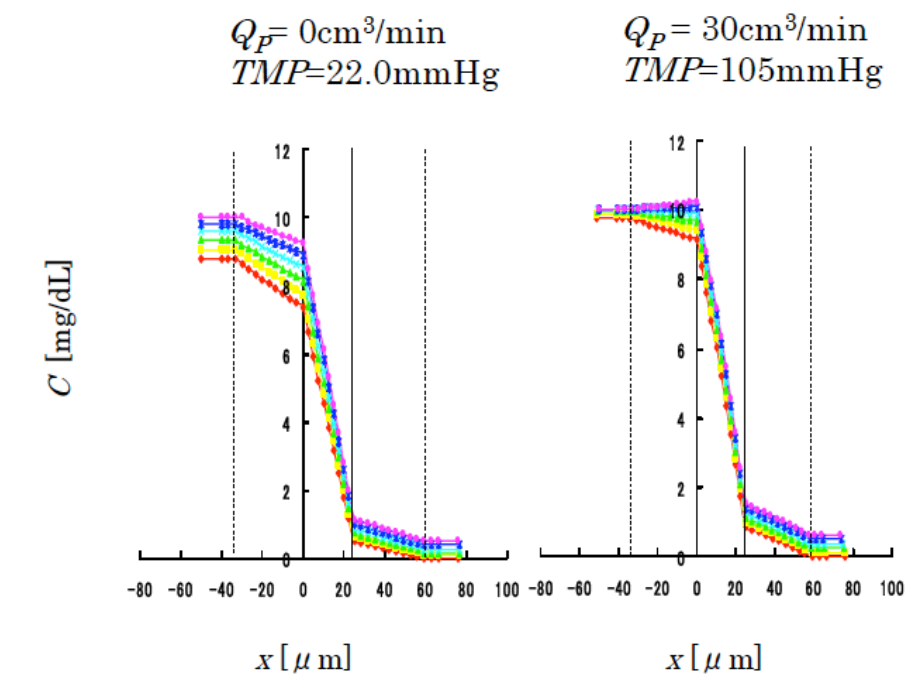

$$
\begin{aligned}
& Q_{P}=60 \mathrm{~cm}^{3} / \mathrm{min} \\
& T M P=188 \mathrm{mmHg}
\end{aligned}
$$

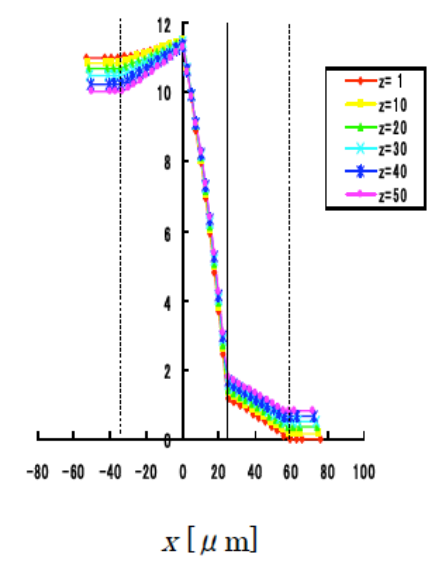

Figure.4: Solute concentration profiles of myoglobin for $L_{P}=15$ hemodiafilter.

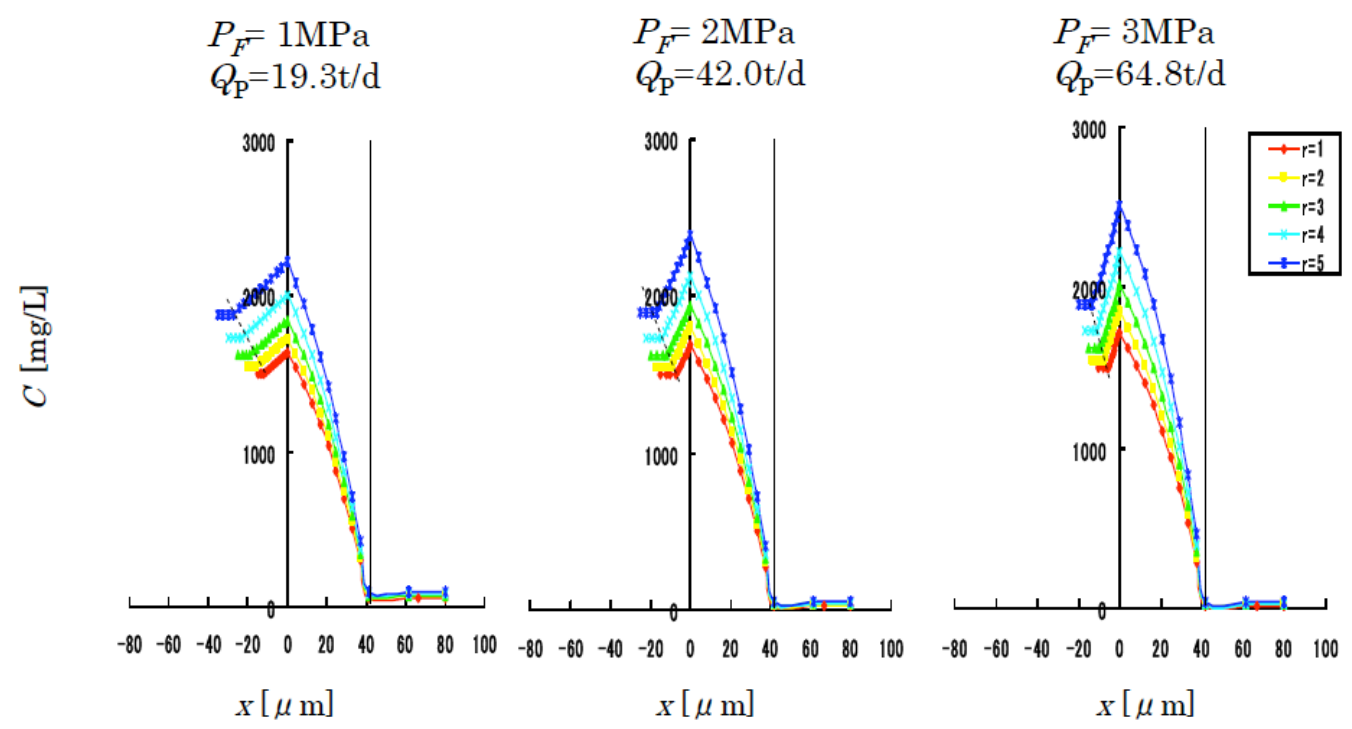

Figure 5: Solute concentration profiles of $\mathrm{NaCl}$ sol. for brackish water desalination type reverse osmosis module. 


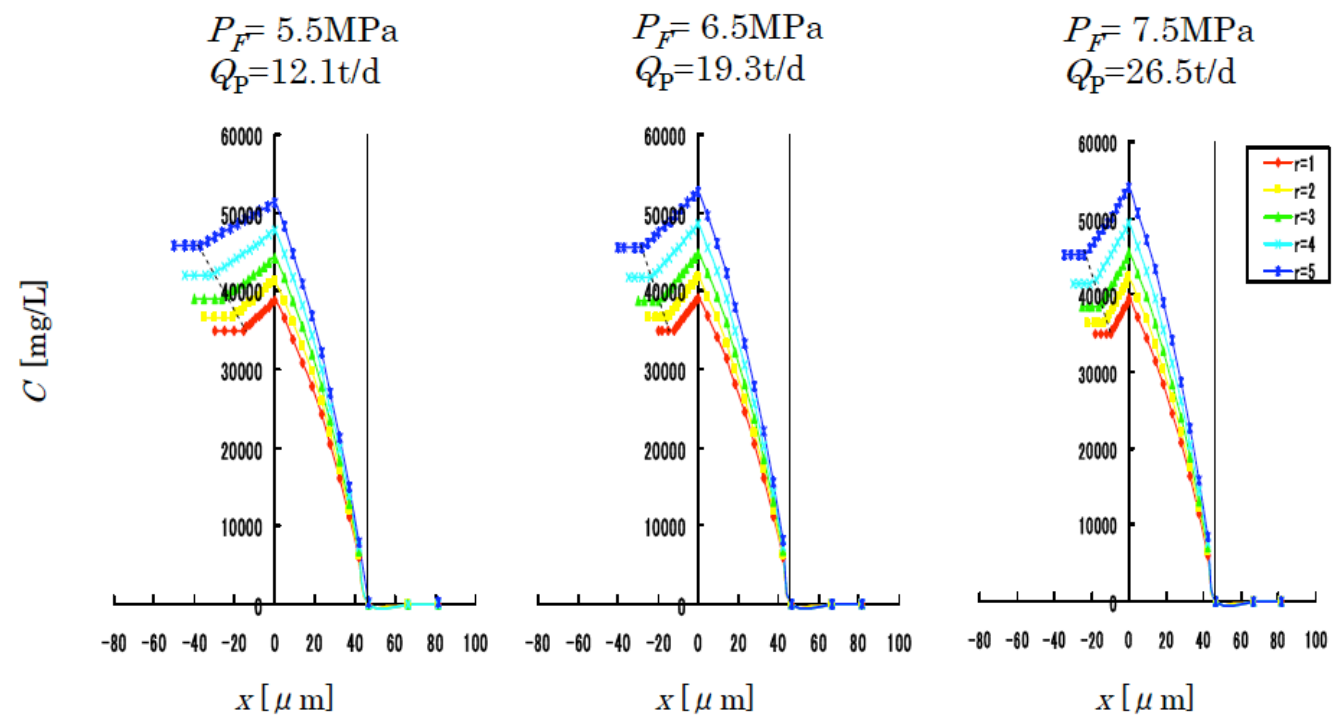

Figure 6: Solute concentration profiles of $\mathrm{NaCl}$ sol. for seawater desalination type reverse osmosis module.

Table 3: Example of Computer Output

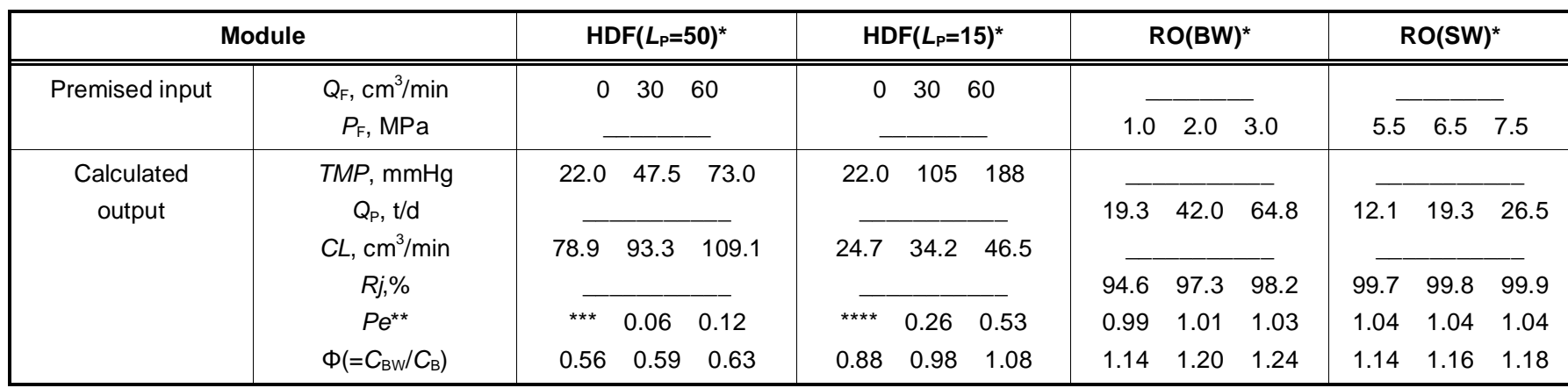

$\operatorname{HDF}\left(L_{P}=50\right)$; High flux type hemodiafilter, $\operatorname{HDF}\left(L_{P}=15\right)$; Conventional type hemodiafilter, $R O(B W)$; Brackish water desalination type $R O, R O(S W)$; Seawater desalination type $\mathrm{RO}$.

${ }^{* *} P e$ in $\mathrm{RO}$ is defined as $\frac{J_{\mathrm{V}}}{B} \cdot \frac{C_{\mathrm{P}}}{C_{\mathrm{BW}}}$.

${ }^{* * *} P e=-1.72 \times 10^{-3}{ }^{* * * *} P e=-2.18 \times 10^{-3} ;$ minus is due to back filtration.

polarization coefficient $\Phi\left(=C_{\mathrm{BW}} / C_{\mathrm{B}}\right)$ is more than 1.0 . Numerical analysis results as this paper reported of the solute transfer could not be found before, because previous researches have focused on overall performances of the module, rather than on partial values such as solute concentration profiles. Therefore, a comparative discussion with other works was not included here.

\section{CONCLUSIONS}

The membrane transport model based on the modified Kedem-Katchalsky equation with the concentration polarization model could be applied to the hemodiafilter and the reverse osmosis module. The solute transport equation could be derived from this membrane transport model for obtaining the solute concentration profiles in the membrane and the boundary layers. Study of the solute transport through membrane was carried out by combining the solute transport equation into the module analysis model.

As a result, the phenomena of solute concentration polarization were able to be shown clearly and consistently through the hemodiafiltration to the reverse osmosis. It was found that the Peclet number and the local mass transfer coefficients significantly contribute to the concentration polarization. So it is considered that this numerical analysis on the solute transfer will be very useful to improve the design of the hollow fiber and module geometries and shell-side flow patterns, etc. by controlling the solute concentration profiles.

\section{ACKNOWLEDGEMENTS}

The author is grateful to Mr. C. D. Tuck for his review and kind advices. 


\section{NOMENCLATURE}

$$
\begin{aligned}
& A=\text { pure water permeability } \mathrm{kg} /\left(\mathrm{m}^{2} \mathrm{sPa}\right) \\
& B=\text { solute permeability } \mathrm{m} / \mathrm{s} \\
& C=\text { solute concentration } \mathrm{mg} / \mathrm{L} \\
& C L=\text { solute clearance } \mathrm{cm}^{3} / \mathrm{min} \\
& D_{\mathrm{L}}=\text { diffusion coefficient } \mathrm{m}^{2} / \mathrm{s} \\
& D_{\mathrm{M}}=\text { membrane diffusion coefficient } \mathrm{m}^{2} / \mathrm{s} \\
& D_{\mathrm{O}}=\text { outer diameter of fiber bundle } \mathrm{m} \\
& d_{1}=\text { inner diameter of hollow fiber } \mathrm{m} \\
& d_{\mathrm{Im}}=\text { logarithmic mean diameter of hollow fiber } \mathrm{m} \\
& d_{0}=\text { outer diameter of hollow fiber } \mathrm{m} \\
& J_{\mathrm{S}}=\text { solute flux through membrane } \mathrm{kg} /\left(\mathrm{m}^{2} \mathrm{~s}\right) \\
& J_{V}=\text { ultrafiltration flux through membrane } \mathrm{m} / \mathrm{s} \\
& K, k=\text { mass transfer coefficient } \mathrm{m} / \mathrm{s} \\
& L=\text { fiber length } \mathrm{m}
\end{aligned}
$$$$
L_{p}=\text { membrane hydraulic permeability }
$$$$
\mathrm{mL} /\left(\mathrm{m}^{2} \mathrm{hrmmHg}\right)
$$$$
L_{\mathrm{s}}=\text { fiber length in tube sheet } \mathrm{m}
$$$$
N=\text { number of hollow fibers }
$$$$
P \quad=\text { applied pressure } \mathrm{Pa}
$$$$
P e=\text { Peclet number }
$$$$
P_{\mathrm{m}}=\text { membrane diffusive permeability } \mathrm{m} / \mathrm{s}
$$$$
Q=\text { flow rate } \mathrm{m}^{3} / \mathrm{s}
$$$$
R c=\text { recovery ratio }
$$$$
R e=\text { Reynolds number }
$$$$
R j=\text { salt rejection }
$$$$
S=\text { membrane surface area } \mathrm{m}^{2}
$$$$
S c=\text { Schmidt number }
$$$$
T=\text { temperature }
$$$$
t=\text { membrane thickness } \mathrm{m}
$$

$$
\begin{aligned}
& x=\text { radial coordinate } \mathrm{m} \\
& z=\text { axial coordinate } \mathrm{m} \\
& \Delta=\text { defference } \mathrm{m} \\
& \Pi=\text { osmotic pressure } \mathrm{Pa} \\
& y=\text { solute convective coefficient } \\
& \delta \quad=\text { boundary layer thichkness } \mathrm{m} \\
& \sigma \quad=\text { reflection coefficient } \\
& \sigma_{\mathrm{P}}=\text { packing density of hollow fibers } \\
& \varepsilon \quad=\text { void fraction (1- } \sigma_{\mathrm{P}} \text { ) } \\
& \Phi=\text { concentration polarization coefficient }
\end{aligned}
$$

\section{Subscripts}

$\mathrm{B}=$ blood-side or feed-side $(\mathrm{RO})$

$\mathrm{BW}$ = blood-side membrane surface

$\mathrm{D} \quad=$ dialysate-side

$\mathrm{DW}=$ dialysate-side membrane surface

$\mathrm{F} \quad=$ filtrate $(\mathrm{HDF})$ or feed $(\mathrm{RO})$

$\mathrm{O}=$ overall

$\mathrm{P} \quad=$ permeate

\section{REFERENCES}

[1] Kedem O, Katchalsky A. Thermodynamic analysis of the permeability of biological membranes to non-electrolytes. Biochemica et Biophysica Acta 1958; 27: 229. http://dx.doi.org/10.1016/0006-3002(58)90330-5

[2] Spiegler KS, Kedem O. Thermodynamics of hyperfiltration (reverse osmosis): criteria for efficient membranes. Desalination 1966; 1: 311-26. http://dx.doi.org/10.1016/S0011-9164(00)80018-1

[3] Villarroel F, Klein E. Holland F. Solute flux in hemodialysis and hemofiltration membranes. T Am Soc Art Int Org 1977; 23: 225-32. http://dx.doi.org/10.1097/00002480-197700230-00061

[4] Kimura S, Sourirajan S. Analysis of data in reverse osmosis with porous cellulose acetate membranes used. AIChEJ 1967; 13: 497-503.

http://dx.doi.org/10.1002/aic.690130319

[5] Jaffrin MY, Ding L, Laurent JM. Simultaneous convective and diffusive mass transfers in a hemodialyser. J Biomech Eng T Asme 1990; 112: 212-19. http://dx.doi.org/10.1115/1.2891174

[6] Zydney AL. Bulk mass transport limitations during high-flux hemodialysis. Artif Organs 1993; 17: 919-24. http://dx.doi.org/10.1111/j.1525-1594.1993.tb00403.x 
[7] Kimura S. Transport equations and coefficients in the re verse osmosis process. Proc $4^{\text {th }}$ Int Symp on Fresh Water from the Sea 1973; 4: 197-206.

[8] Kimura S. Analysis of reverse osmosis membrane behaviors in a long-term verification test. Desalination 1995; 100: 7784.

http://dx.doi.org/10.1016/0011-9164(96)00009-4

[9] Sekino M. Precise analytical model of hollow fiber reverse osmosis modules. J Membrane Sci 1993; 85: 241-52. http://dx.doi.org/10.1016/0376-7388(93)85278-5

[10] Sekino M, Yagi T. Tamamura N. New analytical model and its applications for hemodiafilter. Kagaku Kogaku Ronbun 2010; 36: 34-40.

http://dx.doi.org/10.1252/kakoronbunshu.36.34
[11] Fukuda M, Hosoya N, Kanamori T, Sakai K, Nishikido J, Watanabe T, Fushimi F. Determination of optimal fiber density of conventional and high performance dialyzers. Artif Organs Today 1992; 2: 205-14.

[12] Colton CK, Analysis of membrane processes for blood purification. Blood Purificat 1987; 5: 202-51. http://dx.doi.org/10.1159/000169472

[13] Keller $\mathrm{KH}$. Fluid mechanics and mass transfer in artificial organs. Georgetown: Georgetown Univ Press 1973.

[14] Kumano A, Sekino M, Matsui Y, Fujiwara N, Matsuyama H. Study of mass transfer characteristics for a hollow fiber reverse osmosis module. J Membrane Sci 2008; 324: 13641

http://dx.doi.org/10.1016/j.memsci.2008.07.011

DOI: http://dx.doi.org/10.6000/1929-6037.2013.02.02.3

(C) 2013 Masaaki Sekino; Licensee Lifescience Global.

This is an open access article licensed under the terms of the Creative Commons Attribution Non-Commercial License (http://creativecommons.org/licenses/by-nc/3.0/) which permits unrestricted, non-commercial use, distribution and reproduction in any medium, provided the work is properly cited. 